\title{
Biyografik Bir Roman Örneği Olarak Füreya ve Yakın Tarihimize Işık Tutan Figüratif Yapısı
}

\author{
Vedat Yeşilçiçek* \\ Uşak Üniversitesi, Fen Edebiyat Fakültesi, Uşak.
}

$\ddot{O} z$

Roman, 2000-2005 yillar arasında Remzi Kitabevi tarafindan 64 kez, 2005-2007 yilları arasında ise Everest Yayınları tarafindan $4 \mathrm{kez}$, toplamda $68 \mathrm{kez}$ basılmıştır. Füreya adlı gerçek bir kahramanın yaşam evrelerini üç ana bölümde inceleyen bu roman, Füreya karakterinin hayatına giren ve yakın tarihimizin bilinen önemli isimlerini konu etmesi bakımından önemlidir. Romanın kaynakça, son söz ve fotoğraf albümü bölümü haricinde 40 ayrn alt bölümden oluştuğu görülür. Hem Türk edebiyatının hem de Türk tarihinin ihtiyaç duyduğu ve daha sağlıklı bilgilere ulaşmak için son derece önemli olan "biyografik" çalışmalar; ait olduklar dönemle ilgili çok özel bilgilere ulaşabileceğimiz kaynak çalışmalar özelliği de taşımaktadırlar. Füreya romanı, ihtiva ettiği olaylar bütünü ve vaka açısından modern Türk romancllığı için önem taşımaktadır.

Anahtar Kelimeler: Roman, Biyografik Roman, Füreya, Tarih.

\section{Füreya as an Example of Biographical Fiction and It's Figurative Stucture that Enlightens Turkey's Recent History}

\begin{abstract}
The novel was published 64 times by "Remzi Kitabevi" between 2000-2005, 4 times by "Everest Yayinlarl" between 2005-2007, 68 times in total. This novel mentions the life stages of a real-life character named Füreya in three main sections. The novel has gained importance due to mentioning famous names of our recent history that also comes into her life. The novel consists of 40 different subsections apart from the bibliography, afterword and pictures. While "Biographical" studies are very important for providing more reliable information on both Turkish literature and Turkish history, they are also notable in terms of the specific information presented about the period they belong to. Füreya, with respect to the the narrative forms and techniques is significant for the modern Turkish literature.
\end{abstract}

Keywords: Novel, Biographical Fiction, Füreya, History.

\section{GİRİş}

\subsection{Kulin ve Biyografik Roman}

Ayşe Kulin'in ilk romanı olan, Adr: Aylin romanından başlayarak hemen bütün romanlarındaki vaka tertipleri birbirini anımsatır. Eserlerinde, merkeze aldığı bir ana kahramanın etrafında gelişen olaylar akışa yön verirken, bu olaylara farklı yapıları ile hayat veren diğer kahramanların oluşturduğu vaka zinciri, anlatıyı zenginleştirerek genişletir (Yeşilçiçek, 2010).

Adı: Aylin'de (Kulin, 1997) Aylin romanın merkezindedir. Ailesi, kardeşi, eş(leri), sevgilileri, dostları vb. karakterlerle romandaki olaylar çeşitlenerek zenginleşir. Aylin'le ilişkili olduğu oranda romana dâhil olan her kahraman ve onun gerçek hayatına dair unsurlar, okuyucuya sıradan bir anlatımının dışında, gerçek kahramanların merkezde olduğu biyografik bilgiler aktarmak için kullanılır. Roman 
türünün barındırdığı bu imkân ve çeşitliliği Çetişli; "insan galerisi” (Çetişli, 1999: 254) benzetmesi ile tanimlar.

Yazar, bu romanda verdiği gerçek isim ve bunlara bağlı gelişen olayları, gerçek tanıkların-kahramanların- ağzından anlatır. Örnek olması bakımından: Aylin'in ablası Nilüfer, yakın tarihimizin tanınan siyasi bir ismi olan Kasım Gülek'in ikinci eşidir. Romandaki Giritli Mustafa Naili Paşa, yine gerçek kimliği ve kişisel özellikleri ile Osmanlı'dan Cumhuriyet'e geçişte değişen sosyo-kültürel yapının unsurlarını yüklenen taşıyıcı bir figür olarak romana konu olur.

60'a yakın baskı yapmış olan Sevdalinka (Kulin, 1999) adlı eserinde de Kulin, benzer bir anlayışla karşımıza çıkar. Tamamen gerçek olaylardan hareket ederek yazdığ romanın konusu ile ilgili araştırmalar yaptığını söylemektedir (Yeşilçiçek, 2010).

Romanda olaylar, Eylül 1986'da Saraybosna'da başlatılır ve gün be gün kronolojik gelişmelere riayet edilerek bir vaka tertibi içerisinde ele alınır. Başat kahraman Nimeta'nın etrafında gelişen olaylar içerdiği gerçek kişiler ve olaylarla dokümanter bir hüviyete bürünür.

Senaryoya dönüştürülerek, TV dizisi olan ve uzun süre ekranlarda kalarak büyük ilgi toplayan Köprü (Kulin, 2001) romanı da benzer özellikler taşır. 2001'den itibaren 50'ye yakın baskı yapmış olan romanın ana kahramanı dönemin Erzincan Valisi'dir. Roman; çalışkan, özverili, vatansever bir valinin hizmet mücadelesini, özellikle de yöre halkı için çok gerekli olan ve Fırat nehri üzerinde yapılması düşünülen bir köprünün inşa sürecini konu edinir. Bu süreçte bir yandan bürokratik engellerle mücadele eden vali, öte yandan devletin bu tür hizmetlerini engellemeye çalışan bölücü terör örgütüne karşı verdiği amansız mücadele ile romana konu olur.

2002'den itibaren 17 basımı gerçekleşen Nefes Nefese (Kulin, 2002) adlı romanında da Alman zulmüne maruz kalmış Yahudilerin kurtuluşu için mücadele veren yirmi Türk diplomatın ismi ve verdikleri diplomatik mücadele, "500. Y1l Vakf1 Türk Musevileri" kaynak gösterilerek romana yansıtılır.

Roman, Yahudilere karşı İkinci Dünya Savaşı sırasında uygulanan soykırıma direnen ve onlara yardım eden Türk diplomatlarının hatıralarından esinlenerek kaleme alınmıştır (Yeşilçiçek, 2010).

"Ankara 1941" başlıklı bir bölümle başlayan romanın, "tarihsel gerçeklik" üzerine oturtulmuş vaka tertibi, dönemin cumhurbaşkanı İsmet İnönü'nün o dönemdeki diplomatik çabaları ve savaştan uzak durma gayreti etrafında şekillenir. Başarılı genç bir diplomat olan Macit ve eşi Sabiha'nın bu süreçte yaşadıkları olaylar, bir yönüyle iç dünyalarındaki özel problemler, entrik unsurları beslemek maksadı ile romana yansitılırken, Macit'in bir diplomat olarak yaşadıkları ise romanda, ülkenin içinde bulunduğu sıkıntılı siyasi durumunu okura yansıtmak için kurgulanmıştır.

2005 tarihinden itibaren beş ayrı basımı yapılan Bir Gün (Kulin, 2005) romanı da gerçek kişileri temsil eden iki kadın karakterin -Nevra adlı kadın gazeteci, Zeliha Bora adlı tutuklu Kürt milletvekili- görüşmeleri ve tartışmalarından oluşur. Halen 
ülkemizde sorun olmaya devam eden ayrılıkçı terör örgütü ve hedeflerinin bu iki kadın karakter tarafından tartışılması romandaki olayların özetidir. Kulin, bakış açısını okura yansitırken, bu iki karakter üzerinden geriye dönüşler yapar. Buradaki gerçek hayat kesitlerinden hareketle okuyucusuna bir mesaj verir.

Aslında birbirini tamamlayan iki roman olan Veda (Kulin, 2007) ve Umut (Kulin, 2008) adlı eserleri de tamamen biyografik özellikler taşır. Senaryolaştırılarak yine dizi formatına dönüştürülen bu romanlarda vaka tertibi ve konu, Osmanlı'nın son dönemi ve Cumhuriyet'in ilk yıllarındaki "geçiş" sürecidir.

$\mathrm{Bu}$ birbirinden çok farklı sosyo-kültürel süreç, onu yaşayan gerçek kahramanların yaşam öyküleri bağlamında romanlara yansıtılır.

Osmanlı'nın son döneminde vekâleten Maliye Nazırlığı yapmış olan Ahmet Reşat adlı kahraman ve ittihatçı bir genç olan yeğeni Kemal etrafında gelişen olaylar, taşıdıkları biyografik ayrıntılarla zenginleşerek gelişir.

Umut adlı romanda ise Bosnalı önemli bir ailenin reisi olan Zeki Salih'in Bursa'ya göç etmesi ve burada şekillendirdiği yeni hayat konu edilir. Roman, Veda romanının kahramanı Ahmet Reşat'ın sürgünden dönüşü ile bu romanın devamı hüviyetine bürünür.-romanın üçüncü bölümünden itibaren- Romandaki gerçek karakterler ve onların anılarından oluşan vaka tertibi, esere biyografik bir kimlik kazandirır.

1941 yılında doğan Ayşe Kulin, tüm bu romanlarda anlattığı olaylara, mensubu olduğu ailesinden dolayı aşinadır. Anlattığı, birçok kahramanı yakından tanıyan Kulin, diğerlerini ise yakın akrabalarının anlatımları ve arşivleri sayesinde öğrendiğini, bu yolla tanıma imkânı bulduğunu ifade eder.

Bu bağlamda, Kulin'le 2010 yılında yapılan mülakatta aile köklerini ihtiva eden bir şemayı gösteren yazar, aslında anlattığı, daha doğrusu romanlaştırdığı anlatıların kaynağına işaret etmektedir (Yeşilçiçek, 2010).

\subsection{Biyografik Bir Roman Olarak Füreya}

Roman, yazarın bilgi kaynaklarına ithafen yazdığı bir teşekkür bölümünün ardından, "Şakir Paşa Ailesi”nin soy kütüğü şemasını vererek başlar.

Romanın birinci bölümü “Ada'da ve Bursa'da Zaman” başlığını taşır. Alt başlığı ise romanda daha sonra sıkça tekrarlanacak olan "Pentimento" adını taşır. Pentimento, yağlı boya tablo kazındığında altından çıkabilecek ikinci hatta üçüncü resim anlamina gelmektedir.

Eserin başat kahramanı gerçek bir kişilik olan Füreya'dır. Füreya, yazarın diğer romanlarında karşımıza çıkan kadın kahramanlar gibi, maddi erekleri uğruna birçok şeyi göze alabilecek bir kişiliktir. Füreya'da bu anlamda Kulin'in diğer kadın kahramanları gibi başına buyruk, delifişek bir o kadar akıllı ve zeki olmakla beraber, özel hayatlarında bir türlü aradığını bulamayan mutsuz bir kahramandır. 
Dolayısıyla Füreya'nın ilk evliliği hüsranla sonuçlanır. Ancak ikinci evliliği ile girdiği çevre ve bu çevreyi bütünleyen figüratif yapı romanın biyografik yönünü de ortaya koyar.

Roman Füreya'nın, 26 Ağustos 1992'de Osmanoğlu kliniğine (Kulin 2000) yatırılışı ve bu süreçte mazisine döndüğü bir iç monologla başlar. Daha sonra roman "flashback"lerle gelişerek devam eder. Füreya'yı bu anımsamalar girdabına sürükleyen imge hasta odasının pervazına konan "kuş"tur ve bu imge romanın sonuna kadar varlığını sürdürür.

Kuş imgesi, roman boyunca Füreya'nın ruh dünyasını ve yaşadığı çalkantılı hayatın anlatımına aracılık eder. Romanın sonunda "kuş"un uçup gitmesi ise adeta Füreya'nın ruhunun uçması şeklinde metafizik bir imaja dönüşür. Füreya, gerçek hayatında dünya çapında sanatsal sergiler açan ve yine dünya çapında ilgi görmüş çalışmaları olan bir seramik sanatçısıdır. Kuş figürü de onun eserlerinde çok sık kullanılan bir imge olarak karşımıza çıkmaktadır.

Romanın girişindeki şu monolog tespitlerimizi doğrular niteliktedir.

“... Ama ben böyle geniş kanatlı kuşlar yapmadım ki hiç. Benim yoğurduklarım narin bedenli, küçük başll, uslu, durağan kuşlard. Her an uçmaya hazır değil de uzun bir yolculuktan geri dönmüş hissi veren yorgun kuşlar. Sahi neden benim kuşlarım durgun ve yorgundu hep? Onları yapmam ömrümün sonbaharına denk geldiği için mi?" (Kulin, 2000: 3).

Yazar, bu türden monologlarla Füreya'nın etrafında şekillenen insan galerisini okurlarla tanıştırır. Böylelikle okur, kökleri Osmanlıya dayanan elit bir ailenin ve zümrenin yaşam biçimleriyle de karşılaşmış olur. Boşnak, Gürcü, Libyalı, Suriyeli elitlerin vücuda getirdiği bu kozmopolit yapı, birbiriyle evlenen, aile kuran, ortak bir kültür oluşturan özellik arz eder. Bu Osmanlı'nın imparatorluk ve çok ulusluluk kimliğiyle de örtüşür. Mekân olarak İstanbul, bu ortak kültürün neşv ü neva bulduğu özel bir alan olarak karşımıza çıkar.

Romanın bir diğer kahramanı olan Sara, annesi tarafından Suriye'lidir ve Füreya'nın halasıdır. Bütün hayatını ve malvarlığını eşi öldükten sonra iki erkek kardeşi Cevat ve Şakir'in eğitimi ve yetişmesi için harcamıştır. Bu soydan gelen Füreya, daha sonra Paşa rütbesine gelecek olan Şakir Paşa'yı -büyük dedesi- ve Büyükada' daki konağını şöyle anlatır:

“Cennet, bir cami ile bir kilise arsinda kalan bir yere inşa edilmiş üç katl ahşap bir Osmanlı konağı idi” (Kulin, 2000: 25).

Roman bu konağın seçkin ahalisinin portreleri ve bu portrelerin yaşadıkları olaylar dizini ile zenginleşip gelişecektir. Bu dönem gerçek zaman olarak Cevat Paşa'nın azledilmesi, Girit'e oradan da Şam’a 5. Ordu komutanlı̆̆ına gönderilmesine (1895) tekabül eder. Cevat ve Şakir Paşa'ların geçmişleri üzerine bina edilmiş roman, Osmanlının son döneminde elit bir ailenin aile bağlarını, yaşam tarzlarını, eğitimlerini vb. konuları işleyerek derinleşir. Füreya bu ailenin yakın zamana ait üyesidir. Cevat ve 
Şakir Paşa'lar ise uzak zamana ait üyeleridir. Yazar bu iki zaman dilimi arasındaki vaka zincirini bir tarihi belgesel düzleminde romana yansitır.

Savaş, ailenin yaşam koşullarını güçleştirince Şakir Paşa Afyon'da bulunan mülklerini satmak için yola çıkar. Ancak halen nedeni bilinmeyen bir şekilde oğlu Cevat tarafından öldürülür. Cevat, daha sonra Bodrum'a sürgün edilecek olan ve bugün Halikarnas Balıkçısı olarak tanınan ünlü hikâye yazarımızdır.

1914-1916 yılları Füreya için tam bir felaket dönemidir. Bu kasvetli ve umutsuz dönem, romana Mustafa Kemal Atatürk'ün faaliyetlerinin dahil edilişi ile tekrar umuda dönüşür.

Mustafa Kemal'in işgalden 2 ay önce İstanbul'a gelişi, Şişli' de bir ev kiralayarak faaliyetlerini sürdürmesi romana konu olur. Ancak İzmir'in 15 Mayıs 1915'teki işgali, romandaki diğer hüzünlü hadiseler kuşağını temsil etmektedir.

Roman, Füreya'nın hasta yatağında yaptığı flash-back'ler ve anımsamalarla derinleşir. Bu kronolojik geri dönüşlerde önemli portrelerle karşılaşırız. Bunlardan en önemlisi Füreya'nın babası Emin Bey'in evinde, Atatürk'ün önderliğinde yapılan gizli toplantılarda karşımıza çıkar. Füreya ilk kez Atatürk'ü küçük yaşlarda burada görecektir. Bu durum romana şöyle yansır:

“Tanrım! Onlar nasıl gözler öyle. Masmavi, çakmak çakmak bakışlar. Füreya'yı delip yüreğine saplandı sanki. O hiç bu kadar güzel bir erkek görmemişti bugüne kadar" (Kulin, 2000: 69).

Roman, anımsamalar ve iç monologlar yoluyla gelişirken, Füreya'nın Bursalı bir çiftlik ağası ile sırf maddi nedenlerle yaptığı evlilik, esere ayrıntılı bir biçimde konu edilir. Ancak Füreya'nın bu evliliği son derecede sorunludur. Hatta evliliği esnasında şiddet görür. Füreya'nın maddi saiklerle başlayan ve şehvet duyguları ile bir süreliğine devam eden bu evliliği daha sonra zor da olsa sona erer.

Füreya'nın ikinci evliliği Atatürk döneminin en güçlü ve en çok tartışılan isimlerinden birisi olan "Kılıç Ali" ile yaptığı evliliktir. Bu evlilik ve bu evlilik süresince yaşanan olaylar, vaka tertibini sürükleyen karakterler, romanın biyografik yapısına son derecede önemli katkılar sağlar.

Kurtuluş Savaşı'ndan sonra Füreya'nın babası Emin Bey'le Atatürk'ün arası açılmıştır. Ancak Yalova'da yaşanan bir karşılaşma hem var olan küslüğü ortadan kaldırmış hem de Füreya'nın Kılıç Ali'yle evliliğinin önünü açmıştır.

Füreya'nın Kılıç Ali ile evliliği romana onun Ankara yılları olarak yansır. Bu yeni çevre, özünde yeni yönetim biçiminin ve devletin kurucu fertlerinin teşekkül ettirdiği son derecede önemli bir çevredir. Atatürk'e ve onun yakın çevresine bu evlilik yoluyla nüfuz eden Füreya, Atatürk'ün son iki ayında -ölümüne yakın- ona en yakın olan ve bu süreci en yakından takip eden birkaç kişiden biridir. Bu süreçte, Füreya Atatürk'ün yakın çevresinde Cumhuriyetle şekillenen yeni Türkiye sürecini idrak etmiş, özellikle Atatürk'ün önderliğinde gelişen inkılapların uygulamalarını yakından görme ve değerlendirme imkânı bulmuştur. Bu durum Füreya'nın fikri yapısının 
teşekkül etmesine, çağdaşlaşma ve yeni bir medeni ülke inşa etme projesine bir yönüyle şahitlik etme ayrıcalığına sahip olmasına yol açacaktır.

Romanın biyografik yapısı bakımından hem bu dönem hem de Atatürk'ün ölümünden sonraki dönem önemlidir. Atatürk'ün ölümü Kılıç Ali'nin eski etkisini ve yetkisini ortadan kaldırır. Bir köşeye itilir. Kılıç Ali bunun nedeni olarak İsmet İnönü'yü görmektedir. Ancak Füreya aynı kanaatte değildir. Ancak bu çelişkili durum Füreya'yı Kılıç Ali'den uzaklaştırmaz. Kılıç Ali'nin eski eşinden olan dört oğluna müşfik bir anne olur. Özellikle Altemur Kılıç'la kurduğu anne oğul ilişkisi dikkat çekicidir. Böylelikle roman yakın tarihimizin önemli simalarının yaşam biçimlerini ve bir yönüyle özel yaşamlarını konu eden bir belgesel anlatı niteliğine bürünür.

$\mathrm{Bu}$ dönemde yaşanan farklı olaylar da romanın vaka tertibini besleyen diğer olaylar olarak karşımıza çıkar. İzmir suikastı, Şeyh Sait İsyanı gibi konular özellikle romana konu edilir.

Babasını öldürmekle suçlanan ve idama mahkûm edilen Cevat Şakir Halikarnas Balıkçısı- Kılıç Ali'nin çabaları ile idamdan kurtulur ve Bodrum'a sürgüne gönderilir. Bir yönüyle edebiyat tarihini de ilgilendiren bu süreç de ilginç bir detay olarak romana yansir.

Romanın 10. Bölümü "Yüzleşmeler" adını taşır ve Füreya'nın ailesi içerisindeki tatsız olayları konu eder. Babasının rahatsızlığı nedeniyle Viyana'ya tedavi görmek üzere gidişi, Aliye adlı akrabasının Berger'in sevgilisi Maria'yı vurması, dayısının dedesini vurduğu o karanlık yıllarla örtüşünce Füreya, bu olaylar ve olayların vuku bulduğu aile çevresi için şu değerlendirmeyi yapacaktır:

"Sonuçta birbirini yiyen züppeler, katiller, çllgınlar barındıran bir aile" (Kulin, 2000: 116).

Füreya, bu çalkantılı dönemdeki zorlukları ve bozulan ruh halini, çocukluk yıllarında tanıştığı Atatürk'ün, o yıllarda defterine el yazısı ile düştüğü bir not olan "Memlekete faydalı olunuz" cümlesini hatırlayarak atlatacaktır.

Füreya'nın bu çalkantılar içerisinde verem hastalığına yakalanması, tedavi süreci ve bu hastalığı yenişi, romana önemli bir ayrıntı olarak yansır. Romanın mekânı bu süreçte Paris'tir. Kulin'in romanlarına konu ettiği bu aile ve bu ailenin sosyokültürel bağlantıları, bir boyutuyla daima Paris ve Avrupa'nın diğer önemli merkezleri ile bağlantılıdır. Bu elit çevrenin çocukları, özel eğitim alarak büyümekte, Fransızca başta olmak üzere birkaç yabancı dili erken yaşta öğrenmekte, piyano, bale gibi Batı'ya ait sanat dalları ile küçük yaştan itibaren hemhal olmaktadırlar. Burada dikkat edilmesi gereken husus, Tanzimat romanlarından itibaren bir eleştiri unsuru olarak karşımıza çıkan bu durumun, Kulin'in romanlarında gerçek kişiler üzerinden gerçek yaşam öyküleri olarak kurgulanıyor olmasıdır.

Romandaki zaman unsuru yakın döneme doğru yaklaştıkça, Füreya'nın farklı yönleri de romana yansımaya başlar. 1960'lı yıllarda, ihtilalin hemen öncesinde gençlerin sokak gösterilerine katılan Füreya, bir aktivist karakter olarak karşımıza çıkar. Kulin bu ayrıntıları, romanına konu etmesinin nedeni, gerçek bir kişilik olan 
Füreya'nın farklı karakter yapısını, mücadeleci kimliğini ön plana çıkarmak, öte yandan da ideolojik duruşunu tanımlamak amacına yöneliktir. Hem Füreya'nın hem de Kulin'in dünyaya bakışlarını temsil eden bu ayrıntılar, romanın yapısal ayrıntısındaki "bakış açısı" durumunu da izah eder. Füreya'nın bu aktivist ve devrimci tavrı, romana şu şekilde yansır:

“Soğuk bir günde, bir taksi şoförünün yanına oturmuş, Şişli'ye gidiyordum. 'Aaa kar yağıyor' demiş̧im uçuşan kar tanelerine bakıp.

-İnşallah taş da yă̆ar, demişti çember sakallı şoför

-Niye taş yağsin oğlum, ne günahımız var ki, diyecek olmuştum

-Böyle Allah'tan uzak olunca, taş da yağar, cehennem de gelir, bu memleket baştan aşă̆̆ yıkılir.

Anladım benim için söylüyordu. Çünkü beyaz saçlarıma inat dudaklarım boyalıydl, süslüydüm. Ne çok vardı bu adamlardan çeoremde. Sanki bir anda yerden biterek, şehrin tüm taksilerine el koymuşlardı. Uzun mantolu tesettürlü kadınlar ise 'medeni' değil de Müslüman olduğumu anladıklarında, ters ters bakıyorlardı yüzüme. Ben ki inanılmaz bir coşkuyla yaşamıştım deorimleri, ülkemin insanlarının aydınlığa çıkışına, bilimle, sanatla buluşmasına kadının kimlik kazanmasına tanıklı etmiştim... Tanrım al beni artık al, al!"

(Kulin, 2000: 385-386)

Füreya'nın bu toptancı siyasi ve "ötekileştirici” tavrı, aslında o dönemde biçimlenen ve halen etkilerini gördügüumüz yanlış siyasi algının izlerini taşmaktadır. Füreya'nın bu kabul edilmesi mümkün olmayan ve siyasi bir anlam barındıran değerlendirmesinin Atatürk ve inkılaplarla bağdaştırılıyor olması ise halen yaşadığımız ve çözümleyemediğimiz sosyo-siyasal bir öğreti olarak varlığını sürdürmektedir.

Roman Füreya'nın dayısı Cevat Şakir'in ölümünü hatırlaması ve pervaza konan kuşun onu daveti ile son bulur.

Kulin romana konu ettiği bu karakterleri zaman zaman "dramatik metot" zaman zaman da "açıklamalı metodun" imkanlarıyla okurla buluşturur.

$\mathrm{Bu}$ anlamda yazarın Füreya karakterini çizerken kullandığ1;

"Ben hiçbir yere gitmiyorum hala. Yakında bu yataktan kalkıp, işlerimin başına döneceğim.

Sergim var yakında. Sizinle gelemem ben." (Kulin, 2000: 6)

Şeklindeki monolog yine:

“Bir sır saklar gibi saklamışım duygularımı tam seksen iki yıl... Çok yalan söyledim sana kuş... Çok önceleri böyle saklı değildi duygularım. Sevgiler, hayranlıklar coşkuyla fışkırırdı yüreğimden. (...) Sevdam, iyi niyetim, umudum ve kaybettiğim çocuğun acısının yüreğime sivri uçlu kırık cam parçaları gibi battı̆̆ı günlerde yirmi yaşındaydım..." (Kulin, 2000: $14)$.

Şeklindeki monologlar Füreya'nın karakteristik yapısını ortaya koyması bakımından önemlidir. 
Roman sürükleyici bir karakteri olan Şakir Paşa'da romanda ayrıntılı bir şekilde ele alınır. Onun hayatı ve ilişkileri romandaki biyografik yapıyı besleyen önemli unsurlardandir.

"Şakir Paşa, Sultana küs kalmanın bedelini ağır biçimde ödemekteydi. Ada'ya Türk çocukları için bir ilkokul ve bir Müslüman mezarlığı yaptırdıktan sonra, odasına kapanıp tarihini yazmaktan başka uğraşı kalmamıştı. Tek eğlencesi 1900'lerin başında, Abdülhamit'e şu veya bu şekilde kırılmış ya da onun gadrine uğramış diğer küs paşalar ve bürokratlarla buluşup, nargile içmekti. (...) Osmanlı tarihinin yazımı, büyük bir disiplin içinde, sayfa sayfa ilerlerken, geniş ailenin mali gücü de adım adım gelişmekteydi.

Şakir Paşa Afyon civarından büyük bir arazi satın almıştır. (...)" (Kulin, 2000: 24-25).

Yine, romana Atatürk'ün en güçlü karakterlerden biri olarak dahil olması çok önemlidir. Füreya'nın aslında ona yakın olmak için Kılıç Ali'yle evlenmesi, dolayısıyla Kılıç Ali'nin güçlü bir karakter olarak romana yansımasına vesile olur.

Kulin bu durumu,

"Ve şimdi Füreya, bu evlilikle her gün onu görebilme, ona yakın olabilme firsatın yakalayacaktı. Ondan feyz alacaktı" (Kulin, 2000: 164) cümleleriyle anlatır.

Romana Füreya'nın sanat çevresini şekillendiren isimler olarak giren, Sabahattin Eyüboğlu, Bedri Rahmi, Yaşar Kemal, Ahmet Hamdi Tanpınar, Aloş lakabıyla bilinen Ressam Teoman Germaner gibi isimler, seramik sanatının, Utarit İzgi, Hamdi Şensoy, İlhan Teregün, Muhlis Türkmen gibi önemli ismleri, D grubu sanatçıları..vb romanın biyografik yapısına önemli katkılar sağlar.

\section{SONUÇ}

Hatıra, biyografi, monografi gibi çalışmalar tam anlamıyla tarihi bir belge sayılmasalar da ihtiva ettikleri bilgilerle tarihe ve tarihi olaylara 1şık tutarlar. Bu tür metinlerin barındırdığı ve çoğunlukla özel-tek yönlü- bir bakış açısı ile verilen bilgiler, tarihi metin ve belgelerin sunduğu gerçeklikle örtüştüğünde, söz konusu olayların farklı yönleri ortaya çıkar. Bireysel anlatıların hâkim olduğu bu türden metinlerdeki samimiyet, tarihi metinlerdeki resmi ve keskin üslubun dışında, daha 1lımlı ve çekici bir tavırla okuyucu ile buluştuğunda tesiri daha kalıcı ve etkileyici sonuçlar doğurmaktadır.

Edebiyat tarihimizde önemli bir yeri olan Cevat Şakir'in resmî belgelerdeki yaşam öyküsünün yanında bu romana yansıyan öyküsü arasındaki fark, bir yanlışlama veya doğrulamanın ötesinde, aynı öykünün farklı bir tertip ve üslupla anlatımından ibarettir.

Kılıç Ali, Altemur Kılıç, Bedri Rahmi, Sabahattin Eyüboğlu vb. önemli isimlerin kısmi hayat öykülerinin bir aile ve cemiyet ilişkisi içerisinde bu türden anlatılarla okurla buluşması, az önce de belirtildiği gibi daha kalıcı ve tesirli bir öğrenme sürecine vesile olacaktır.

Tarihi bir kronolojinin didaktik üslubunun dışına çıkılarak, mütareke yıllarının romanda anlatılıyor olması, bu yıllarda Atatürk'ün faaliyetleri, yine Atatürk'ün son 
yıllarına tekabül eden siyasi ve sosyal olaylar, romana tarihi bir kimlik kazandırırken, bu olayların ana kahramanlarının bir karakter olarak vakaya dahil olması okuyucuya farklı bir bilgilendirme imkânı vermektedir. Böylelikle, biyografik bir hüviyet kazanan bu türden eserler, geniş okur kitlelerine ulaşabilmekte ve farklı bir öğrenme sürecinin işlemesine neden olmaktadır.

\section{KAYNAKÇA}

Çetişli, İ., (1999). Memduh Şevket Esendal (İnsan ve Eser). Kardelen Kitabevi. Isparta.

Kulin, A. (1997). Adı Aylin. Evrensel Yay. İstanbul.

Kulin, A. (1999). Sevdalinka. Everest Yay. İstanbul.

Kulin, A. (2001). Köprüu. Everest Yay. İstanbul.

Kulin, A. (2002), Nefes Nefese. Everest Yayınları. İstanbul.

Kulin, A. (2005).Bir Gün. Everest Yayınları. İstanbul.

Kulin, A. (2007). Veda. Everest Yayınları. İstanbul.

Kulin, A. (2008).Umut. Everest Yayınları. İstanbul.

Yeşilçiçek, V. (2010). Ayşe Kulin'in “Hayatı, Sanatı, Eserleri” (Basılmamış Doktora Tezi). Çanakkale Onsekiz Mart Üniversitesi Sosyal Bilimler Enstitüsü. 